\title{
Health surveillance of preschool children: four years' experience
}

\author{
Allan F Colver
}

Abstract

Objectives-To monitor the implementation of a programme of health surveillance for preschool children and measure its effect on child health.

Design-Regular reporting to primary care teams of their own performance, and determining the overall effect of the programme on children in the district.

Setting-All practices in Northumberland health district.

Subjects-All children of preschool age in Northumberland ( 3600 births each year).

Main outcome measures-Proportion of eligible children immunised and screened for abnormalities. Age at diagnosis of congenital deafness, cerebral palsy, and special educational needs.

Results-Over $90 \%$ of eligible children were covered by the health surveillance scheme. Child health improved over the four years after the scheme was implemented. Uptake of immunisation against measles rose from $68 \%$ to $93 \%$ of eligible children, and the average age at which congenital deafness was diagnosed fell to 9 months.

Conclusions-Maintaining the effectiveness of a surveillance programme and reporting this back to primary health care teams are processes which themselves improve health.

\section{Introduction}

In 1986 agreements made in Northumberland health district about the principles and content of a health surveillance programme for preschool children were reported.' The agreements had arisen from discussions with every practice, clinical medical officer, and health visitor in the district. They were similar in principle and content to the recommendations given in Health for All Children, ${ }^{2}$ which was written after discussions between representatives of the Royal College of General Practitioners, the Health Visitors Association, the British Paediatric Association, the General Medical Services Committee of the BMA, and the Royal College of Nursing.

The agreements made in Northumberland have been implemented for four years. We report the results of their implementation and hope that they will be useful to district health authorities and family practitioner committees planning their own programmes for surveillance-programmes that will have to be adopted by general practitioners who seek remuneration under the proposed changes in their conditions and services. ${ }^{3}$

Beaconhill Children's Centre, Cramlington, Northumberland NE23 8EH

Allan F Colver, MRCP, consultant paediatrician (community child health)

\section{Methods}

AGREEMENTS FOR HEALTH SURVEILLANCE

The main agreements made in Northumberland district have been reported before.' Briefly, health surveillance was divided into three components (education, screening, and assessment of problems) and was the responsibility of the primary health care team - namely, the family doctor, health visitor, and clinical medical officer. It was agreed that:

(1) Routine developmental screening examinations should not.be undertaken, but a few screening tests
Examples of data sets that could be used to evaluate health surveillance schemes

DEVELOPMENTAL GUIDANCE AND HEAITH FDUCATION Immunisation uptake

Data on accidents:

Hospital admissions

Attendances at accident and emergency department

Attendances at general practices

Survey by questionnaire of parental knowledge of services for families, management of illness, etc

\section{SCREENING AND ASSESSMENT}

Uptake of screening test

Average age at diagnosis and treatment of congenital deafness

Average age at which children with cerebral palsy start receiving therapy

Age at which help is offered to children who became the subject of an educational statement - that is, designated as having special teaching requirementsbefore they are aged 6

Delay in treating phenylketonuria or hypothyroidism

Average age at which children with a congenital cataract are referred

Average age at which therapy is started for children with a specific delay in developing language severe enough to require a statement of educational need before they are aged 6

Number of children whose need for an operation for congenital dislocation of the hip is diagnosed after the age of 6 weeks

Proportion of boys undergoing orchidopexy before the age of 6

Number of children starting school with an unidentified squint

Average age at which children are referred for surgery for acyanotic heart disease

Average age at which children are referred with severe growth hormone deficiency

should be performed, each test being defined with a clear referral pathway for children who failed it. The tests agreed in Northumberland differed slightly from those recommended in Health for All Children. Northumberland district agreed to specific tests for language for children aged 18 months and 3 years, and it decided to measure the height of children aged 4 years, whereas Health for All Children recommends measuring 3 year olds. The Northumberland district surveillance programme does not include retesting for testicular descent after 6 weeks.

(2) Health staff should have an aide mémoire of topics to discuss with parents at the time of each screening test and at consultations for other reasons if appropriate. Staff were reminded that it is better to do a small programme well on all children than to do a large programme poorly on some children.

(3) Training in health surveillance is essential and should be undertaken on a district basis, linked to local policy and procedures.

(4) Monitoring and evaluation of the performance of 
primary health care teams and regular reporting back of data must be an intrinsic part of the programme.

\section{APPROACH TO EVALUATION}

It is impossible to evaluate all aspects of a surveillance programme: some aspects are difficult to assess, and collecting all relevant data is time consuming and expensive. It is important, however, to begin the process of evaluation and to build on this as information systems start to run smoothly. The box gives some examples of data that can be collected to evaluate surveillance. We collected data on immunisation uptake, screening tests, average age at diagnosis of congenital deafness, and average age at which therapy was given to children with cerebral palsy or special educational needs. Data were obtained from Northumberland's births, immunisation, and preschool surveillance database and its register of children with special needs.

Some measurements, such as immunisation uptake, are suitable for year by year comparisons both within and between districts. Other measurements, such as those that depend on the local policy for implementing the 1981 Education Act, are not suitable for comparison between districts.

\section{Results}

Since the agreements were introduced four years ago no doctor or health visitor has said that they are unworkable or should be abandoned. Two training courses on surveillance for family doctors and clinical medical officers in Northumberland have been fully subscribed and have been attended by 50 doctors. A principal in general practice from 40 of the 57 practices in the Northumberland district has attended the course.

In 1984 the details of immunisation uptake were reported and each primary health team was given its own figures and comparative data for other primary health care teams in the district. Figure 1 shows how the district's uptake of immunisation against measles increased from $68 \%$ in 1984 to $93 \%$ in 1989 (in 1984, 1981 births were reported in the district and Northumberland had the worst uptake in the Northern region).

$\star$ Roughly 900 children were included in each three month cohort. Children who moved into the district after the age at which they should have been screened were not included in the target cohort.

TABLE II - Average age (months) at which physiotherapy was started for children with cerebral palsy in Northumberland health district

\begin{tabular}{lcc}
\hline \multirow{2}{*}{$\begin{array}{l}\text { Type of } \\
\text { cerebral palsy }\end{array}$} & \multicolumn{2}{c}{ Year of birth } \\
\cline { 2 - 3 } & $1970-7$ & $1978-85$ \\
\hline Quadriplegia & $6 \cdot 5$ & $6 \cdot 5$ \\
Diplegia & 23 & 10 \\
Hemiplegia & 21 & 12
\end{tabular}

TABLE III - Number of children who were subject of statement of educational need before age 6 who first received help at age

\begin{tabular}{lrrr}
\hline & \multicolumn{3}{c}{ Year of birth } \\
\cline { 2 - 4 } $\begin{array}{l}\text { Age } \\
\text { years })\end{array}$ & 1980 & 1981 & 1982 \\
\hline$<2$ & 17 & 22 & 21 \\
$2-$ & 2 & 3 & 2 \\
$3-$ & 1 & 4 & 1 \\
$\geqslant 4$ & 9 & 2 & 5 \\
\hline
\end{tabular}

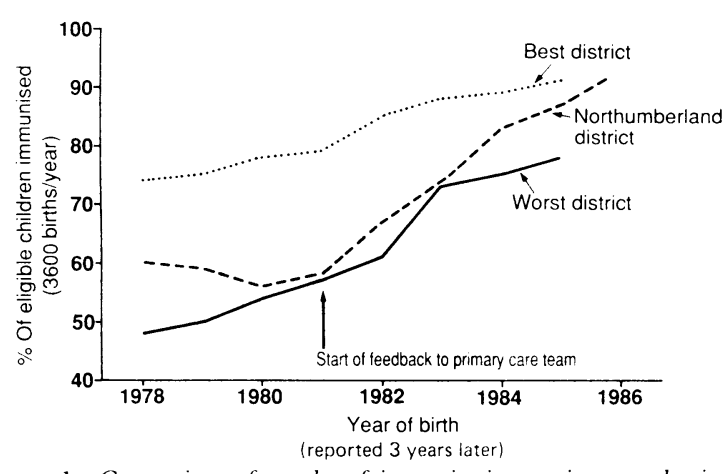

FIG 1-Comparison of uptake of immunisation against measles in Northumberland district and other districts in Northern region

Comparable improvements occurred for immunisation against diphtheria, tetanus, polio, and pertussis: 54 of the 57 primary health care teams in Northumberland district achieved over $90 \%$ uptake of immunisation against diphtheria, tetanus, and polio in 1989 , whereas in 1984 only 22 practices achieved this.

Data on the screening tests performed were recorded on computer from June 1987, and table I shows the changes in the proportion of children screened in successive three monthly cohorts. Figure 2 shows how the average age at which congenital deafness was recognised and at which hearing aids were fitted has fallen. The striking recent improvement bears an exact

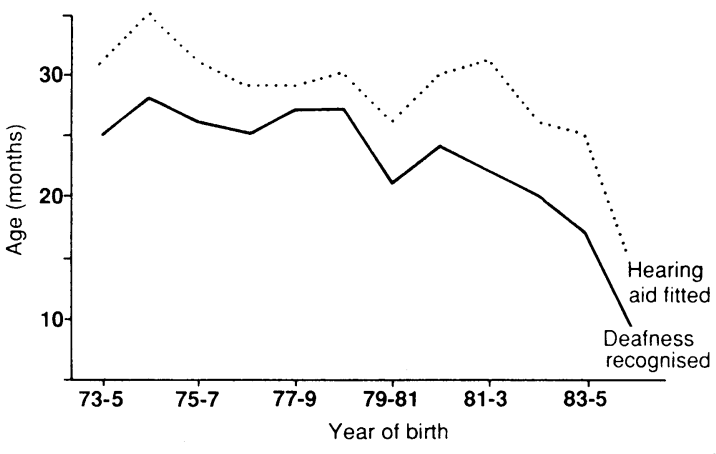

FIG 2-Age of children in Northumberland district at detection of congenital deafness and when hearing aids were fitted. Figures are three year rolling averages. Deafness $>60 \mathrm{~dB}$ in better ear

temporal relation to the introduction and evaluation of the agreements in Northumberland.

Table II shows the average age at which physiotherapy was started for children with cerebral palsy and table III the ages at which help was offered to children who became the subject of a statement of special educational need before they were aged 6 . It is too early to relate these changes to the new agreements, but the data reported illustrate the information systems that must be set up at the outset of the programme.

\section{Discussion}

The main reason why the health surveillance of preschool children in the United Kingdom is so disorganised is that its effect has never been evaluated. Little scientific evidence exists to justify many of the activities undertaken and few data are available to indicate whether surveillance programmes reach the whole child population or lead to improved fiealth.

The evidence presented here shows that the primary health care teams in Northumberland district have done what they agreed to in $1986^{1}$ and that the programme of surveillance is being delivered to over $90 \%$ of children. Further, there is evidence of improving health, as judged by better immunisation uptake and earlier recognition and treatment of impairments.

Small difficulties associated with the content of the programme, professional disputes, and accuracy of data have been easily resolved because the agreements were sought, not imposed; disputes were resolved by the primary care team itself, not by directives from managers or the family practitioner committee; and data were stored and analysed on a local computer system so that they could be reported at a rate and in a manner that is meaningful and flexible and, when necessary, could be tailored to the needs of an individual practice.

A striking improvement in immunisation uptake occurred in Northumberland during the study, probably because data on uptake were collected and reported back to primary health care teams. Comparable improvements did not occur in the rest of the region. The improvements in the number of children being screened showed a similar influence of feedback. The fall in the average age at which deafness was diagnosed also seems to have occurred as a result of the introduction of the agreements for surveillance and reporting back of data. Thus evaluating the surveillance programme by monitoring its effectiveness and reporting this back to primary care teams itself improves child health.

The study provides probably the first evidence that the recommendations given in Health for All Children work in practice and improve health. We urge family practitioner committees and district health authorities to make Health for All Children the basis for their surveillance programmes. 
Although surveillance programmes may need to vary a little between districts to take account of local needs, there are several advantages in a core programme: the training of doctors and nurses could be standardised across the country, the surveillance of children who moved to another health district would not be affected, and primary health care teams who look after children from more than one health district would not have to vary their programme to suit the child's district of residence.

1 Colver AF, Steiner $\mathrm{H}$. Health surveillance of preschool children. Br. Med 7 1986:293:258-60.

2 Hall DMB, ed. Health for all children. A programme of child health surveillance. Oxford: Oxford University Press. 1989.

3 Department of Health. The National Health Service general medical and pharmaceutical services) regulations. London: $\mathrm{DoH}, 1989$.

(Accepted 24 January 1990)

\section{Audit in Person}

Brighton Health Authority, Brighton General Hospital, Brighton BN2 3EW

J Bennett, MFCM, consultant in public health medicine $\mathrm{K}$ Walshe, BSC, research coordinator, CASPE

Research

Correspondence to: Dr Bennett.

\section{Occurrence screening as a method of audit}

\section{J Bennett, K Walshe}

Brighton Health Authority has been actively pursuing a district wide quality assurance programme for almost five years since it first adopted a formal quality assurance strategy in $1985 . .^{2}$ As part of that programme clinicians within the district, in cooperation with CASPE (Clinical Accountability, Service Planning and Evaluation) Research, have experimented with various approaches to medical audit. One of these techniques, developed in the United States and known as occurrence screening or screening criteria, has shown considerable promise and will form the basis of a hospital wide trial of medical audit at the district's main acute hospital.

Occurrence screening is based on two main principles: firstly, that it is far more practical to specify and describe what does not constitute good quality care

TABLE I-MMA screening abstract * than to specify what does; and, secondly, that focusing attention and resources on the investigation and analysis of instances of poor quality of care is an effective way to bring about improvement in overall standards of care. The specification and description of what does not constitute good quality care is set out in a set of screening criteria. The criteria are designed to highlight cases in which the patient experiences an adverse event or circumstance which, under optimal conditions, is not a natural consequence of his or her disease or treatment. ${ }^{3}$ Such an event is sometimes termed an adverse patient occurrence. ${ }^{4}$ Screening criteria may be generic or specific to particular specialities, conditions, or procedures. They are generally selected by the clinicians concerned with their use and may be based on clinical experience,

\begin{tabular}{|c|c|c|c|c|c|}
\hline \multirow[t]{2}{*}{$\begin{array}{l}\text { Date variation } \\
\text { identified }\end{array}$} & \multicolumn{2}{|r|}{ Element } & \multirow[t]{2}{*}{$\begin{array}{l}\text { Date variation } \\
\text { identified }\end{array}$} & \multicolumn{2}{|r|}{ Element } \\
\hline & 1 & Admission for adverse results of outpatient management & & 12 & Other patient complications \\
\hline & 2 & $\begin{array}{l}\text { Readmission for complications or incomplete } \\
\text { management on previous hospitalisation }\end{array}$ & & 13 & $\begin{array}{l}\text { Hospital-incurred patient incident: } \\
\begin{array}{ll}\text { (a) Falls and accidents } & \text { (d) Skin problems }\end{array}\end{array}$ \\
\hline & \multirow[t]{2}{*}{3} & \multirow{2}{*}{$\begin{array}{ll}\text { Operative consent: } \\
\begin{array}{ll}\text { (a) Incomplete } & \text { (d) Different surgeon } \\
\text { (b) Missing } & \text { (e) Not signed by patient } \\
\text { (c) Different from } & \text { (f) No consent note } \\
\text { procedure done } & \text { (g) Other }\end{array}\end{array}$} & & & (c) Medication problems (f) Other \\
\hline & & & & 14 & $\begin{array}{l}\text { Abnormal laboratory, radiographic, or other test results } \\
\text { not accessed by physician }\end{array}$ \\
\hline & \multirow{2}{*}{4} & \multirow[b]{2}{*}{$\begin{array}{l}\text { Unplanned removal, injury, or repair of organ } \\
\text { or structure during surgery, invasive procedure, or } \\
\text { vaginal delivery }\end{array}$} & & 15 & Neurological deficit not present on admission \\
\hline & & & & 16 & Transfer to another acute care facility \\
\hline & \multirow[t]{2}{*}{5} & \multirow{2}{*}{$\begin{array}{l}\text { Unplanned return to operating or delivery room on this } \\
\text { admission }\end{array}$} & & 17 & Death \\
\hline & & & & \multirow[t]{2}{*}{18} & \multirow{2}{*}{$\begin{array}{l}\text { Subsequent visit to emergency room or outpatient } \\
\text { department for complications or adverse results of this } \\
\text { hospitalisation }\end{array}$} \\
\hline & \multirow[t]{2}{*}{6} & \multirow{2}{*}{$\begin{array}{l}\text { Surgical and other invasive procedures not } \\
\text { meeting criteria for necessity and appropriateness. } \\
\text { (a) Pathology report or preoperative diagnosis mismatch } \\
\text { (b) Non-diagnostic tissue } \\
\text { (c) No tissue } \\
\text { (d) Other }\end{array}$} & & & \\
\hline & & & & 19 & $\begin{array}{l}\text { Utilisation management variations from criteria for } \\
\begin{array}{ll}\text { (a) Length of stay } & \text { (c) Other } \\
\text { (b) Resource utilisation } & \end{array}\end{array}$ \\
\hline & \multirow[t]{2}{*}{7} & \multirow{2}{*}{$\begin{array}{l}\text { Transfusion reactions, complications, and } \\
\text { improper utilisation } \\
\text { (a) Transfusion occasioned by atrogenic bleeding or } \\
\text { anaemia } \\
\text { (b) Transfusion not clinically indicated } \\
\text { (c) Transfusion reaction }\end{array}$} & & 20 & 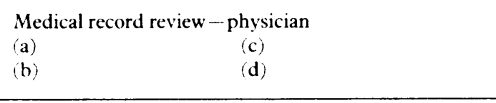 \\
\hline & & & & 21 & $\begin{array}{l}\text { Medical record review - nursing } \\
\text { (a) }\end{array}$ \\
\hline & 8 & \multirow{2}{*}{ Nosocomial (hospital acquired) infection } & & & \\
\hline & & & & 22 & Departmental or other problems \\
\hline & 9 & $\begin{array}{l}\text { Antibiotic/drug utilisation which is unjustified, excessive, } \\
\text { results in patient injury, or varies from approved criteria } \\
\begin{array}{ll}\text { (a) } & \text { (b) }\end{array}\end{array}$ & & 23 & Patient or family dissatisfaction \\
\hline & 10 & Cardiac or respiratory arrest or low Apgar score & & & \\
\hline & 11 & $\begin{array}{l}\text { Transfer from general care to special care unit } \\
\begin{array}{ll}\text { (a) Complication } & \text { (b) Utilisation prohlem }\end{array}\end{array}$ & \multicolumn{3}{|l|}{ Comments: } \\
\hline
\end{tabular}

${ }^{\star}$ Reproduced with permission from Health Services Management 1989;85:178-81. 